\title{
Two Kinds of A Priori Infallibility
}

\author{
Glen A. Hoffmann
}

Ryerson University

digital.library.ryerson.ca/object/144

Please Cite:

Hoffmann, G. (2011). Two kinds of a priori infallibility. Synthese 181(2), 241-253.

$\underline{\text { doi:10.1007/s11229-010-9800-9 }}$

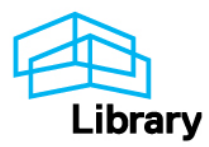




\section{Two Kinds of A Priori Infallibility}

On rationalist infallibilism, a wide range of both (i) analytic and (ii) synthetic a priori propositions can be infallibly justified (or absolutely warranted), i.e., justified to a degree that entails their truth and precludes their falsity. Though rationalist infallibilism is indisputably running its course, adherence to at least one of the two species of infallible a priori justification refuses to disappear from mainstream epistemology. Among others, Putnam (1978) still professes the a priori infallibility of some category (i) propositions, while Burge $(1986,1988$, 1996) and Lewis (1996) have recently affirmed the a priori infallibility of some category (ii) propositions. In this paper, I take aim at rationalist infallibilism by calling into question the a priori infallibility of both analytic and synthetic propositions. The upshot will be twofold: first, rationalist infallibilism unsurprisingly emerges as a defective epistemological doctrine, and second, more importantly, the case for the a priori infallibility of one or both categories of propositions turns out to lack cogency.

\section{Introduction: Rationalist Infallibilism}

On rationalist infallibilism, a wide range of both (i) analytic and (ii) synthetic a priori propositions can be infallibly or absolutely justified, i.e., justified to a degree that entails their truth and precludes their falsity. In particular, on this doctrine, at least two main classes of a priori propositions are susceptible of infallible justification: (i) logical, conceptual and mathematical propositions, and (ii) so-called self justifying propositions. Though rationalist infallibilism is undoubtedly running its course, adherence to at least one of the two species of infallible a priori justification refuses to disappear from mainstream epistemology. Among others, Putnam (1978) still professes the a priori infallibility of some category (i) propositions, ${ }^{1}$ while Burge (1986, 1988, 1996), Lewis (1996) and Bealer (1999) have recently affirmed the a priori infallibility of some category (ii) propositions.

\footnotetext{
${ }^{1}$ Of course, Putnam merely argues that there is at least one infallible a priori truth, what he calls 'the minimal principle of contradiction', leaving open whether there are others (1978, p. 155). Moreover, he claims that this a priori truth is infallibly justifiable in the sense that it is rationally impossible to disbelieve it (1978, pp. 155ff), a kind of infallibility that may or may not be covered by our definition.
} 
In this paper, I take aim at rationalist infallibilism by disputing the a priori infallibility of both analytic and synthetic propositions. There will be two main outcomes of our inquiry. First, rationalist infallibilism predictably emerges as a fundamentally defective epistemological doctrine. Second, more importantly, the case for the a priori infallibility of one or both categories of propositions (erected by rationalists or empiricists) turns out to lack cogency.

\section{Analytic Propositions}

The rationalist quest for infallible certitude often begins and sometimes ends with analytic propositions. There is a long tradition in philosophy, mathematics, the sciences and other disciplines of proclaiming the a priori infallibility of putative logical, conceptual and/or mathematical truths. ${ }^{2}$ While these are not mutually exclusive categories, the following kinds of examples have been tendered:

(Logical Truth)

(Conceptual Truth)

(Conceptual Truth)

(Conceptual Truth) (Mathematical Truth) $\quad 2+3=5$.
Millie is either in the study or not in the study (M $\square \sim \mathrm{M}$ ), Jerry cannot both be a bachelor and married, Zoran cannot be in Moscow and London simultaneously, An object cannot be both blue and green all over at the same time,

In philosophy the infallibility thesis concerning analytic propositions is primarily associated with rationalists such as Descartes (1996) and Frege $(1967,1974)$, but has also been endorsed by empiricists such as Hume (1948), Putnam (1978), Ayer (1936, 1940, 1956), Carnap

\footnotetext{
${ }^{2}$ See Boghossian (1994, p. 117ff) for a brief discussion of this history.
} 
$(1935,1950)$ and some (other) proponents of logical positivism. Whether rationalist or empiricist, the case for the infallibility of logical, conceptual and mathematical propositions is essentially modal in character. At least some propositions in these domains, it is urged, are logically necessary (and thus infallibly justified) truths: they are true on all truth value assignments and false on no truth value assignment. Any straightforward employment of deductive reasoning, the claim runs, yields the transparency of this fact.

On one standard formulation of the modal argument for analytic infallibility it is urged that some logical, conceptual and mathematical propositions have rigid meanings, meanings completely specifiable on the basis of syntactic and semantic principles. ${ }^{3}$ A superficial inspection of the syntax and semantics of sentences expressing such propositions, the reasoning runs, reveals they are true by meaning, and consequently, are necessary truths. For example, the mode of composition and the meaning of the lexical components of 'Jerry cannot both be a bachelor and married' are sufficient to yield the necessary truth, and corresponding infallibility, of the proposition expressed by this sentence.

On another (related) variant of the modal argument it is urged that some logical, conceptual, and mathematical propositions have a special property concomitant with their rigid meaning: they make formally specifiable assertions, assertions whose meanings are wholly specifiable by syntactic and semantic principles (Cf. above). ${ }^{4}$ Since these propositions make formally specifiable assertions, the reasoning runs, they are susceptible of irrefutable proof by way of deductive logic (i.e., the universal laws of classical truth functional logic), a proof that cannot be overturned ex post facto. For example, a four row truth table or the application of two

\footnotetext{
${ }^{3}$ This formulation of the argument is typically advanced in support of the analytic infallibility of so-called conceptual truths. It has been made in some form or another by Kant (1990), Ayer (1936, 1940), and Carnap (1935), among others.

${ }^{4}$ This formulation of the argument is typically advanced in support of the analytic infallibility of so-called logical and mathematical truths.
} 
rules of natural deduction supply irrevocable proof of any assertion of the form $X \square \sim X$, by establishing its truth on any possible truth value assignment.

In spite of its appeal at various periods in history, there is a seemingly decisive rebuttal to the modal argument for the infallibility of analytic propositions. Doubtless, it is acknowledged, some logical, conceptual and mathematical propositions are necessary truths and correspondingly conclusively justified within a specific logical/semantic framework. Presupposing classical truth functional logic, Millie is either in the study or not in the study is a necessary conclusively justified proposition. Presupposing a minimally acceptable semantic framework for logical and non-logical terms, ${ }^{5} 2+3=5$, one cannot be a married bachelor, and an object cannot be blue and red all over at the same time are necessary conclusively justified propositions. The problem, evidently, is that propositions of this kind are not infallibly justifiable (or susceptible of absolute warrant), justifiable to a degree that is truth entailing and falsity precluding. Insofar as logical/semantic frameworks require some kind of confirmation in their own right, reason cannot infallibly justify elementary logical, conceptual and mathematical propositions (or apparently any other analytic proposition). In particular, deductive reasoning falls short in this case since inevitably it fails to establish the truth of the analytic propositions in question on any possible logic, semantics or interpretative standpoint. ${ }^{6}$ Deductive reasoning by its very nature cannot deliver analytic infallibility. ${ }^{7}$

\footnotetext{
${ }^{5}$ By 'minimally acceptable' I have in mind a semantic framework in which, like all standard proposals, logical and non-logical terms have a determinate and consistent reference across all possible worlds. This would rule out bizarre Goodmanian-style logics in which ' + ' might refer to the additive function except in cases where it follows ' 2 ' where it will refer to the subtraction function or in which 'bachelor' refers to an adult unmarried male except in cases where that male is a cultural relativist.

${ }^{6}$ This line of argument has a close kinship with the Quinean repudiation of analyticity (1953) since it impugns analytic infallibility on the basis of the logical defeasibility of all analytic propositions. Needless to say, though, it does not directly confront the viability of the analytic/synthetic distinction.

${ }^{7}$ Although strictly speaking it has not been ruled out that there might be some other way to deliver analytic infallibility.
} 
This well rehearsed line of argument enshrines a view of reason that on the surface looks compelling. In the long standing debate concerning epistemological infallibilism, stretching approximately from Plato to the present, an appealing principle has gained widespread recognition: reason cannot furnish absolute warrant for any analytic proposition. If reason is not an autonomous vehicle of justification, it cannot infallibly justify analytic propositions. But it would seem that reason is not sui generis in this sense. The veracity of reason is not something that can be established ex hypothesi: whether or not reason is being exercised correctly is seemingly insensitive to data. Many, including Klein (2003, pp. 40-42) and Davidson (1986), consider this to be a fundamental defect of foundationalism in general and rationalist foundationalism in particular (infallibilist or otherwise): since reason is not sui generis, it cannot deliver direct unmediated warrant that is transferable to propositions, statements or beliefs.

Leaving to one side the anti-foundationalist invective, minimally the following (weaker) thesis seems to be in order: reason cannot deliver absolute or infallible justification for any analytic proposition since the veracity of reason is not even in principle receptive to evidence. Since the exercise of reason is intrinsically corrigible, it cannot be a guarantor of analytic truth. While it cannot be ruled out that reason might be a candidate for foundational justification of some form or another, it cannot be a vehicle of infallible or absolute justification, at least for analytic propositions.

On closer inspection, the force of the fallibilist view of reason seems to spring, for all intents and purposes, from a falsifiability thesis: any analytic proposition, the truth of which is purportedly established by reason, is susceptible to falsification. Reflection on familiar skeptical hypotheses seems to reinforce the conviction that there is at least one defeasor available for every analytic proposition. Consider some of the radical otherworldly thought experiments 
concocted by skeptics (in the course of defending actual or hypothetical skepticism) to the effect that all of our previous beliefs could turn out to be wrong: e.g., Descartes' evil demon hypothesis, Putnam's brain-in-a-vat hypothesis and Russell's false memory of past experience hypothesis. It is surely conceded by all manner of skeptic, including the radical skeptic, that reason ab initio can deliver the firmest of convictions about the truth of a wide range of analytic propositions. But as the skeptics would have it (at least provisionally), reason cannot justify, certainly not infallibly, belief in such propositions since it cannot be excluded that insidious deception is occurring: an evil demon, a mad scientist or some other omnipotent malevolent force is deceiving us about these and perhaps all other matters. It is a venerable skeptical insight that there is at least one defeasor available for every analytic proposition in the form of an otherworldly skeptical hypothesis.

The hypotheses canvassed by radical skeptics underscore the sense in which the exercise of reason seems to require presupposing its veracity. Evidently, one can never be sure that reason has not misfired since the possibility cannot be completely ruled that one is mistaken about the veracity of reason itself (e.g., when one is deceived by an omnipotent malevolent force). The exercise of reason cannot conclusively establish the falsity of the skeptical hypotheses since by virtually all accounts the veracity of reason itself depends on their falsity. ${ }^{8}$

If there is a way to escape the fallibilist/skeptical problematic, it must involve rejecting some fundamental modal intuitions. The champion of analytic infallibility is essentially required to reject the possible falsity of propositions such as Millie is either in the study or not in the study, Jerry cannot be a married bachelor, $2+3=5$, and the corresponding possibility of an evil demon deceiving us about the truth of these propositions. Such a strategy is likely to involve

\footnotetext{
${ }^{8}$ A great deal of the philosophical import of the radical skeptic's assault on justified belief and knowledge is that it shines light over the most pernicious form of circularity plaguing the rationalist's case for a priori analytic infallibility.
} 
recruiting a broadly pragmatic semantics, found in various forms in the work of Wittgenstein (1969, 10ff), Strawson (1968), Putnam (1978) and others. ${ }^{9}$ On this basic approach, the putative falsity of the analytic propositions in question would be viewed as a variety of semantic error. To allow the falsity of $2+3=5$, Millie is either in the study or not in the study, and the like (or to allow that an evil demon could be deceiving us about these matters), it might be claimed, is merely to misuse the logical and/or non-logical terms contained in such propositions; it involves misconstruing the meaning of one or more of the relevant terms.

Whatever the merits of pragmatic semantics, a concern is that the attempt to dispel deep seated modal intuitions on its basis looks prima facie unpromising insofar as these intuitions do not look to be directly informed by theory (semantic or otherwise). On first blush, semantic theories are in the first instance supported by intuitive modal reflection: i.e., reflection about what is conceivable, acceptable or possible. The standard pragmatic defense of a conception of logical/metaphysical possibility on which the analytic propositions in question cannot be false (and on which radical skeptical propositions are logically/metaphysically impossible), on this count, looks to reverse the natural order of explanatory priority. From this perspective, the analytic infallibilist encounters a stiff challenge in deposing ingrained intuitions concerning the logical possibility of the falsity of analytic propositions.

But even were our opponent to meet the heavy burden of subduing staunch presentiment concerning the possibility of analytic falsehood along pragmatic lines, it is unclear what she will have accomplished. Suppose it turns out that the apparent possibility of analytic falsehood involves some kind of semantic mistake, a misuse of the logical and/or non-logical terms contained in analytic propositions or a misconstrual of their meanings. In this case, the

\footnotetext{
${ }^{9}$ Although none of these philosophers, except perhaps Putnam, can be described as defending a kind of analytic infallibility, some pragmatic semantic maneuver seems to be the only riposte available to the analytic infallibilist in this case.
} 
pragmatist can be understood to have established the rationally impossibility, incoherence or inconsistency of disbelieving propositions such as Millie is either in the study or not in the study, Jerry cannot be a married bachelor, $2+3=5$, and the like. Crucially, though, she would not have established the logical impossibility of analytic falsehood or the logical possibility of analytic infallibility, in the way these concepts are being used. The rational impossibility of disbelieving a (analytic) proposition is equivalent to the logical impossibility of a (analytic) proposition's falsity only on the condition that logical possibility is a species of epistemic possibility, doxastic possibility, psychological possibility or some close cognate. Now while the latter thesis cannot be dismissed outright, and may in fact be thought in some way presumptive of pragmatic semantics, this would not threaten the doctrine of analytic fallibilism.

The bottom line is that granting the pragmatist thesis that the apparent possibility of analytic falsity is a kind of semantic mistake, and the consequent logical possibility $\leftrightarrow$ epistemic possibility thesis, in actuality involves recasting the analytic infallibility/fallibility debate in a way that leaves analytic fallibilism unscathed. Exploiting pragmatic semantics of this type effectively involves redefining the alethic concepts of truth and falsity in anti-realist terms. The problem is that such revisionary semantics, whatever its credentials, undoubtedly forecloses on the possibility of the kind of analytic infallibility under consideration, an infallibility that involves certitude of the highest measure (viz. incorrigible certitude). Wittgenstein, for his part, is happy to acknowledge this point. The brand of pragmatics sketched in On Certainty, Wittgenstein concedes, rules out the possibility of certainty as the concept is ordinarily understood, i.e., in the realist terms of indefeasibility, a concept that connotes "... I can't be wrong" (1969, 7; Wittgenstein's emphasis). 
In short, contra analytic infallibilism, reason cannot infallibly justify analytic propositions. At a minimum, the compelling case for the fallibility of reason, made inter alia by anti-foundationalists and skeptics, effectively raises the specter of a priori uncertainty vis-à-vis logical, conceptual and mathematical propositions (and apparently all other analytic propositions), no matter how faint the specter. Naturally, this does not preclude the a priori justification of logical, conceptual, mathematical or any other analytic proposition tout court, nor that these kinds of propositions might be susceptible of a high degree of a priori justification.

\section{Synthetic Propositions}

The other primary candidates for a priori infallibility include synthetic propositions about the external world, material objects and the self. The former two proposals for synthetic a priori infallibility, canvassed by Descartes (1996, pp. 117ff), C.I. Lewis (1945), Price (1953) and Unger (1975) (among others), have not survived serious scrutiny in my view. Discussion will accordingly be restricted to the third class of propositions: so-called self justifying propositions. ${ }^{10}$

Traditionally, self justifying propositions have been at the heart of the rationalist infallibilist program. For the rationalist, self justifying propositions are those whose sincere assertion is supposed to be a priori sufficient to establish their truth. More specifically, an a priori self justifying proposition is one whose sincere assertion about an extant first person cognitive state - a state internal to a subject - purportedly establishes its truth. Descartes' proposals in

\footnotetext{
${ }^{10}$ Another proposal for synthetic a priori infallibility is the putative ontologically necessary truth to the effect that 'something exists'. I leave open that some such synthetic proposition is an infallibly justified a priori truth. In the event that it is, I minimally revise my view to be that no synthetic a priori proposition of real cognitive import can be infallibly justified.
} 
the Meditations on First Philosophy (1996, pp. 80ff) are the locus classicus for infallible a priori self justification:

(Cogito) I think therefore I exist as a thinking thing and along the same lines

(Dubito) I doubt therefore I exist as a doubting thing.

For Descartes, (Cogito) and (Dubito) are self justifying propositions since they can be thought only if they are understood (their esse is their percipi), i.e., they are objects of thought with which one has direct unmediated comprehension (1996, pp. 80-81).

Independent of whether Descartes' archetypal a priori propositions are in fact self justifying in any interesting normative sense is the question of whether the propositions are susceptible of infallible self justification, i.e., whether their sincere assertion entails their truth and precludes their falsehood. Sustained reflection suggests (Cogito), (Dubito) and analogous proposals for a priori self justification fail on this grade: whatever degree of justification they might turn out to admit falls short of the absolute standard of infallibility.

The focal point of the denial of infallible a priori self justification is a compelling rationale recommended in some form or another by such diverse philosophers as Sellars (1997), Hume $(1739,1948)$, Ayer $(1936,1956)$, Chisholm (1977) and Klein $(1990,1999,2003)$. It is commonly professed nowadays that mental states cannot be vehicles of infallible justification since they cannot ex nihilo guarantee the truth of any fact. Mental states, like third person cognitive states (or observations), cannot be guarantors of truth since any assertion about such a state is of necessity at a remove from it: it involves saying something about the state. In asserting 
something about a mental state (immediate or mediated), it is claimed, the possibility for error inevitably surfaces. As Ayer puts the point (1956, p. 19): "there will not be a formal contradiction in saying both that a man's state of mind is such that he is absolutely sure that a given statement is true, and that the statement is false" ${ }^{11}$ On this view it follows that for any factive mental state $\mathrm{M}$ there is a possible world $\mathrm{W}_{1}$ in which the fact $\mathrm{M}$ is directed towards is false even when the fact $\mathrm{M}$ is directed towards is its own existence.

The fallibilist view of a priori self justification represents, in no small way, a variation of an influential assault on formal foundationalism Sosa has called the doxastic assent argument (1980, p. 13). Sosa condenses the argument as follows (1980, p. 6): ${ }^{12}$

a. (i) If a mental state incorporates a propositional attitude, then it does not give us direct contact with reality, e.g., with pure experience, unfiltered by concepts or beliefs.

(ii) If a mental state does not give us direct contact with reality, then it provides no guarantee against error.

(iii) If a mental state provides no guarantee against error, then it cannot serve as a foundation for knowledge.

(iv) Therefore, if a mental state incorporates a propositional attitude, then it cannot serve as a foundation for knowledge.

b. (i) If a mental state does not incorporate a propositional attitude, then it is an enigma how such a state can provide support for any hypothesis, raising its credibility selectively by contrast with its alternatives.

(ii) If a mental state has no propositional content and cannot provide logical support for any hypothesis, then it cannot serve as a foundation for knowledge.

(iii) Therefore, if a mental state does not incorporate a propositional attitude, then it cannot serve as a foundation for knowledge.

c. Every mental state either does or does not incorporate a propositional attitude.

d. Therefore, no mental state can serve as a foundation for knowledge. (From a(iv), b(iii), and c.)

\footnotetext{
${ }^{11}$ Hume in effect supplies what is perhaps the most fundamental ground for this claim (1739, Book I, part III, section vi): "there is no object, which implies the existence of any other if we consider these objects in themselves, and never look beyond the idea which we form of them".

${ }^{12}$ Naturally there are countless formulations of this argument.
} 
This breed of anti-foundationalism is an unmistakable descendant of Sellars' influential antifoundationalist polemic in Empiricism and the Philosophy of Mind (1997). Cognitive states, whether first person or third person, cannot at once be immediate and informative since assertions about cognitive states are ipso facto afield of them (Sellars, 1997, section 8). For Sellars this means brute first person and third person cognitive states, what he calls 'the given', lack any evidentiary legitimacy (1997, p. 168).

Whatever the case may be regarding the merits of the prevailing anti-foundationalist argument schema, an important lesson can be drawn from it. Whether or not brute cognitive states, first person or otherwise, can be viewed as bona fide forms of evidence or as potential foundational justifiers, the possibility of infallible first person justification looks spurious on the face of it. First person cognitive states cannot be infallible justifiers, it would seem, since any assertion about them necessarily engenders the possibility of faulty inference. It follows mutatis mutandis that no mental state can be infallibly self justifying.

Considering (Cogito) as a case in point, when it is sincerely asserted I think therefore..., the truth of whatever claim follows the ellipsis is never entailed by what precedes it since there is always the possibility a faulty inference is made. There is a conspicuous epistemological gulf between ' $I$ think' and 'I exist as a thinking thing' since in moving from the former assertion to the latter a judgment is made about the proto mental state thought, namely, that there is an $I$ or subject bearing it. At least this is Hume's view of the matter $(1739,1948)$ : (Cogito) cannot be an infallible (or fallible) self justifying proposition since from an epistemological standpoint there is a normative distinction between asserting the existence of thought and asserting the existence of a thinking thing. 
For Descartes, though, Cogito-like propositions are instances of direct unmediated ratiocination that give us irrevocable acquaintance with the reality of the subject. David Lewis (1996, pp. 564ff) similarly construes Cogito-like propositions as pure rational intuitions, minus the Cartesian metaphysics, intuitions that furnish unmediated access to the reality of the subject. For Lewis these intuitions give rise to a specific kind of infallibility regarding subjective reality, an infallibility restricted to the specious present of the subject (what she experiences in the here and now) and that eludes her upon any kind of reflection or second order contemplation (1996, p. $559-561) .^{13}$

If I am correct, neither Descartes' nor Lewis' defense of infallible self justification withstands serious scrutiny. Securing warrant for self reflective judgments about one's own thoughts necessarily involves reflecting on the basis of such judgments — judgments about the content of the proto thought. ${ }^{14}$ And when one reflects on the warrant for a judgment regarding one's thoughts, the thought one is reflecting on is distinct from or independent of the reflecting thought. ${ }^{15}$ Since the numerical independence of these thoughts manifestly implies their epistemological independence, Cogito-like propositions cannot be infallibly self verifying either contextually (e.g., in a way that is restricted to the specious present) or unrestrictedly. ${ }^{16}$ This line of thinking is more or less a direct product of the Humean position concerning purported self verifying judgments such as (Cogito) and (Dubito). (Cogito) and (Dubito) cannot be infallibly

\footnotetext{
${ }^{13}$ This is why for Lewis knowledge about the self, though infallible in some contexts, is intrinsically 'elusive'.

${ }^{14}$ One can rightly claim here that this is exactly the contention Descartes and Lewis reject. For Descartes and Lewis, it is possible to have direct unreflective intuitions about oneself - the professed basis for infallible judgments about the self. The problem with this outlook, as I see it, is that judgment is an essentially normative concept that implies the possibility of being right or wrong and the commitment to supply reasons for one's judgment. This plainly means that judgments, about the self or otherwise, are inherently reflective or discursive in nature.

${ }^{15}$ Lewis in a sense agrees with this latter claim since he concedes that once one reflects on one's first order thought, judgments concerning it are stripped of their infallibility (1996, p. 559-560). For Lewis, though, since one can have direct unmediated intuitions about oneself, one can have an infallible Cogito-like self judgment about one's own thought without reflecting on the first order thought.

${ }^{16}$ Macdonald (2007, p. 369) defends a similar position regarding the nature and limits of self verifying judgments.
} 
self verifying judgments since there is an epistemological gap between the existence of thought/doubt and the existence of a thinking/doubting thing. (Cogito) and (Dubito) must, contra Descartes and Lewis, be (inchoate) inferences since they are falsifiable by at least one proposition the truth of which cannot be excluded in principle: (thoughts and doubts belong to subjects).

While the fallibilist view of self justification is becoming increasingly entrenched, it is not without its detractors (e.g., Burge, 1986, 1988, 1996; Parent, 2007; Lewis, 1996; Bealer, 1999). ${ }^{17}$ Most notably, Burge has recently defended a species of infallible self justification (and knowledge) involving privileged access that has become definitive of the rationalist infallibilist stance concerning self justification. ${ }^{18}$ On Burge's account, privileged access to some first order thoughts about the self is borne out by the reflexive or self referential character of a specific class of second order thought (i.e., thought about one's thoughts). First order thoughts, it is claimed, are logically locked onto their second order counterparts: i.e., they are a proper part of the cognition that constitutes the second order thought. As Burge puts the point (1988, pp. 659-660),

In basic self knowledge, one simultaneously thinks through a first-order thought (that water is liquid) and thinks about it as one's own. The content of the firstorder (contained) thought is fixed by nonindividualistic background conditions. And by its reflexive, self-referential character, the content of the second-order judgment is logically locked (self-referentially) onto the first-order content which it both contains and takes as its subject matter.

\footnotetext{
${ }^{17}$ Note, Burge and Lewis's defenses of infallible self justification (and knowledge) are part of their ambitious project to establish the compatibility of a specific kind of externalism with certain kinds of self justification (and self knowledge), a project that has received considerable attention in the literature on self knowledge in the last few decades (see Parent (2007) and Macdonald (2007)). In the discussion to follow, I bypass debate concerning the possibility of self justification or knowledge as such (i.e., fallible self justification and knowledge) and concerning the compatibility of such knowledge with externalist accounts of intentional content.

${ }^{18}$ Though Burge's account of infallible self justification (and knowledge), we will see, differs from Descartes' account in certain respects. Even so, I will argue it suffers from the same basic defects as the Cartesian account.
} 
On this view, if a subject has a second order thought that (for instance) she thinks $\mathrm{P}$ then she has the first order thought P. This implies, along the lines of (Cogito), that if I have the second order thought 'I am now thinking', the first order thought it contains as a constituent must be true and cannot be false - i.e., it is infallibly justified. ${ }^{19}$

Burge's infallibilism about self justification is predicated on his view of the self referential character of second order thought. The primary thesis in this connection concerns the logical locking of some second order thoughts about the self onto their first order constituents: a subject thinking she thinks P (e.g., I am now thinking that water is a liquid) formally entails she thinks P (Burge, 1996, pp. 95ff). Needless to say, generally speaking, a subject thinking P does not formally entail $\mathrm{P}$. The question, then, is whether self referential thought is an exception to this rule, whether a subject thinking she thinks $\mathrm{P}$ formally entails she thinks $\mathrm{P}$, and if so, why. In my view, Burge's thesis concerning the self referential character of certain kinds of second order thought, whatever it merits, is not a thesis of pure reason that can engender infallible a priori self justification. If some second order thoughts infallibly self refer to their first order constituents, this ostensibly is an empirical fact — one whose infallibility is purchased a posteriori by reflecting on the evidence. After all, the logical locking thesis is certainly not a logically necessary truth: as a matter of pure logic, there can be no guarantee that any second order thought about the self logically locks on to its first order constituent. As Hume effectively showed, there is at least one defeasor vis-à-vis the logical locking thesis, i.e., the negation of Descartes' implicit (Cogito) inference: $\sim$ (thoughts $\rightarrow$ subjects). ${ }^{20}$ If thoughts don't require subjects then second order thoughts about the self don't entail their first order constituents, e.g.,

\footnotetext{
${ }^{19}$ Parent also defends the logical locking thesis (2007, pp. 415ff), but on empirical rather than putative a priori grounds.

${ }^{20}$ In bald terms, the Humean insight is that thoughts $\rightarrow$ subjects is not a logically (or epistemologically) unassailable inference.
} 
the second order thought ' $I$ am now thinking' doesn't imply that ' $I$ am now thinking'. If Burge is to deliver infallible self justification it appears, then, to come at the cost of a priority since he will be required to adduce evidence to confute Hume's dismissal of the (Cogito) inference.

The central problem with Burge's view of self referential justification is that it ignores the inescapable epistemological chasm between thoughts about the self and the subject matter (i.e., subject) of those thoughts. If we are correct, in reflecting on the warrant for a judgment regarding one's thoughts, the reflecting thought is distinct from the reflected thought. This gives rise to an epistemological lacuna that rules out the possibility of infallible a priori self justification. This is just to say, in a manner of speaking, that the logical locking thesis (or any thesis regarding the mechanics of the reference fixing of self referential judgments) is not a logical truth since it is not logically indefeasible. In fact, the logical locking thesis is not even 'relatively uncontroversial' as Burge maintains (1988, p. 660). If Heil (1988, pp. 240-241) and MacDonald (2007, pp. 369-370) are correct, the logical locking thesis is not the most perspicuous way of explaining so-called privileged access or first person authority, the phenomenon in which a subject is supposed to have better epistemic access to her own thoughts than others do. ${ }^{21}$

Parent, unlike Heil and Macdonald, is unwavering in his commitment to the logical locking thesis, and while he rejects Burge's a priori argument for this thesis, does not rule out the possibility of its a priori justification (2007, p. 420). It is perhaps telling, though, that Parent's defense of the logical locking thesis and the corresponding infallibility of self justification (of certain forms) is explicitly a posteriori. The principal basis of Parent's argument for infallibilism about self justification is a thesis (about a Fodorian language of thought) he acknowledges to be

\footnotetext{
${ }^{21}$ As with the debates concerning fallible self justification (and knowledge) and the compatibility of self knowledge with externalism, I evade discussion concerning the possibility, scope and limits of privileged access or first person authority in this paper.
} 
empirical: “...thoughts are composed of concepts according to specific formation and transformation rules, i.e., a 'grammar"' (2007, p. 415). Parent's position regarding infallible self justification obliquely reveals what Burge's attempts to conceal: that infallible self justification cannot be purchased a priori.

In the end, Burge, for reasons similar to Descartes, has failed to furnish us with a brand of a priori infallible self justification that is “... self-referential in a way that insures the object of reference just is the thought being thought" $(1988$, p. 659). This finding should be no real surprise since it is a relatively direct consequence of the fallibilist view of reason, sketched and defended here. If even the most diligent exercise of reason is not failsafe, pure reason cannot deliver any variety of infallible justification, including infallible self justification. Of course, whether (Cogito), (Dubito) and analogous proposals for infallible a priori self justification are amenable to a lesser degree of justification is an entirely separate question.

\section{Concluding Remarks}

If I am correct, pure reason cannot furnish absolute warrant for any kind of proposition. Two direct consequences follow from this recognition. First, rationalist infallibilism, the doctrine according to which a wide range of both analytic and synthetic a priori propositions can be infallibly justified (or absolutely warranted), is completely without merit (contra Descartes (1996), C.I. Lewis (1945), Unger (1974), Price (1953)). Second, and more importantly, the two component theses of rationalist infallibilism lack credibility: neither (i) analytic a priori propositions nor (ii) synthetic a priori propositions can be infallibly justified (contra Putnam (1978), Burge (1986, 1988), Lewis (1996), Bealer (1999), Price (1953) and Unger (1974)). 
On the other hand, no more wide ranging conclusions can be drawn for the origins, structure or possibility of justified belief (or knowledge), since no explicit reason has been given for rejecting alternative fallibilist varieties of rationalism or foundationalism, or, strictly speaking, for rejecting infallibilist empiricism. While it might turn out a compelling dismissal of foundationalism, rationalism and/or infallibilist empiricism can be erected on the basis of the resilient anti-foundationalist/fallibilist insights of Hume, Sellars, Quine and others, final judgment on this matter must be postponed.

\section{References}

Ayer, A.J. (1936) Language, Truth, and Logic. (London: Gollancz).

Ayer, A.J. (1940) The Foundations of Empirical Knowledge. (London: Macmillan).

Ayer, A. J. (1956) The Problem of Knowledge. (London: Macmillan).

Bealer, G. (1999) 'A Theory of The A Priori’. Philosophical Perspectives, 13, pp. 29-55.

(Cambridge, Mass.: Basil Blackwell).

Boghossian, P. (1994) 'Analyticity and Conceptual Truth'. Philosophical Issues, 5, 117-131.

Burge, T. (1986) 'Individualism and Psychology'. The Philosophical Review, 45, 3-45.

Burge, T. (1988) 'Individualism and Self-Knowledge'. The Journal of Philosophy, 85, 649-663.

Burge, T. (1996) 'Our Entitlement to Self-Knowledge'. Proceedings of the Aristotelian Society, 96, 91-116.

Carnap, R. (1935) Philosophy and Logical Syntax. (Bristol, U.K.: Thoemmes).

Carnap, R. (1950) 'Empiricism, Semantics, Ontology'. Revue Internationale De Philosophie, 4, 20-40.

Chisholm, R. (1977) 'The Truths of Reason'. In Theory of Knowledge. (Englewood Cliffs: Prentice-Hall). 
Davidson, D. (1986) 'A Coherence Theory of Truth and Knowledge'. In Truth And Interpretation, Perspectives on the Philosophy of Donald Davidson. (Ed.) E. LePore. (Oxford: Basil Blackwell).

Descartes, R. (1996) Meditations on First Philosophy. (Trans.) J. Cottingham. (Cambridge: Cambridge University Press).

Feldman, R. (1990) 'Klein on Certainty and Canonical Beliefs'. In Doubting: Contemporary Perspectives on Skepticism. (Eds. M. Roth and G. Ross), Kluwer Academic Publishers, pp. 121126.

Frege, G. (1967) Concept Script, a Formal Language of Pure Thought Modelled Upon That of Arithmetic. (Trans. Bauer-Mengelberg) in From Frege to Gödel: A Source Book in Mathematical Logic, 1879-1931. (Ed. J. Van Heijenoort). (Cambridge, Mass.: Harvard University Press).

Frege, G. (1974) The Foundations of Arithmetic. (Trans.) J.L. Austin. (Oxford: Basil Blackwell).

Hume, D. (1739) A Treatise Concerning Human Nature.

Hume, D. (1948) An Inquiry Concerning Human Understanding.

Kant, I. (2007) Critique of Pure Reason. (Trans.) N. Kemp Smith. (Edinburgh: Blunt Press).

Klein, P. (1990) 'Epistemic Compatibilism and Canonical Beliefs'. In Doubting: Contemporary Perspectives on Skepticism. (Eds.) M. Roth and G. Ross. (Kluwer Academic Publishers).

Klein, P. (1999) 'Human Knowledge and the Infinite Regress of Reasons' in Philosophical Perspectives, 13, Epistemology, pp. 297-325.

Klein, P. (2003) 'How a Pyrrhonian Skeptic Might Respond to Academic Skepticism' in The Skeptics: Contemporary Essays. (Aldershot: Ashgate).

Lewis, C.I. (1946) An Analysis of Knowledge and Valuation. La Salle: Open Court.

Lewis, D. (1996) 'Elusive Knowledge'. Australasian Journal of Philosophy, 74(4), 549-567.

Macdonald, C. (2007) 'Introspection and Authoritative Self Knowledge'. Erkenntnis, 67, 355372.

Moore, G.E. (1962) Philosophical Papers. (New York: Collier Books).

Parent, T. (2007) 'Infallibilism About Self-knowledge'. Philosophical Studies, 133, 411-424.

Price, H.H. (1953) Thinking and Experience. (Cambridge, Mass: Harvard University Press) 
Putnam, H. (1978) 'There is at Least One A Priori Truth'. Erkenntnis, 13, 153-170.

Quine, W. (1953) From a Logical Point of View. Cambridge, Mass.: Harvard University Press

Sellars, W. (1997) Empiricism and the Philosophy of Mind. (Ed.) Brandom, R. Cambridge, Mass.: Harvard University Press.

Sosa, E. (1980) 'The Raft and the Pyramid'. In Midwest Studies in Philosophy, 5, Studies in Epistemology, 3-25 (Minneapolis: University of Minnesota Press).

Strawson, P. (1957) 'Propositions, Concepts and Logical Truths'. Philosophical Quarterly, 7.

Unger, P. (1975) Ignorance: A Case for Scepticism. (Oxford: Clarendon Press).

Wittgenstein, L. (1969) On Certainty. (Eds.) Anscombe, E. and Von Wright, G. H. (Oxford: Basil Blackwell) 